\title{
Carcass and meat quality traits of Saanen goat kids reared under natural and artificial systems and slaughtered at different ages
}

\author{
Hulya Yalcintan, Pembe Dilara Akin, Nursen Ozturk, Bulent Ekiz, \\ Omur Kocak, Alper Yilmaz
}

Istanbul University, Veterinary Faculty, Department of Animal Breeding and Husbandry, Istanbul, Turkey

Received December 29, 2017
Accepted June 27, 2018

\begin{abstract}
Production of high-quality carcass and meat from goat kids may contribute to an increase in goat farming profitability. The aim was to compare carcass and meat quality traits of Saanen goat kids raised under natural (NR) and artificial (AR) rearing systems and slaughtered at 80 days and 120 days of age. The AR kids were separated from their dams immediately after birth and were fed with a commercial milk replacer, while the NR kids suckled their mothers. The rearing type did not affect the average daily gain, slaughter weight, hot carcass weight, empty body weight, commercial dressing percentage, subjective conformation and fatness scores. In parallel with the increase in slaughter age, the slaughter weight, hot carcass weight, empty body weight and subjective carcass conformation score increased. The rearing type had no effect on instrumental meat quality traits, except for meat Lightness $\left(\mathrm{L}^{*}\right)$ and Hue values. Meat from NR kids had higher $\mathrm{L}^{*}$ and Hue values $1 \mathrm{~h}$ and $24 \mathrm{~h}$ after cutting than those of AR kids. Warner-Bratzler shear force value increased with the slaughter age, but the meat lightness decreased. The ultimate $\mathrm{pH}$ was generally high in all groups, ranging between 5.94 and 6.10 . The panellists evaluated the meat from NR kids to be more tender and juicy and also gave the highest tenderness scores to the meat obtained from the kids slaughtered at 80 days of age. As a conclusion, the slaughter age may be more determinant than the rearing type in the occurrence of carcass and meat quality characteristics.
\end{abstract}

Goat kids, rearing system, sensory evaluation, instrumental meat quality, age effect

Turkey has a goat population of about 10 million heads which is one of the largest goat populations in the Middle East and Mediterranean countries (FAO 2014). Most of the goat breeds in Turkey are indigenous (Angora, Hair goat, Kilis, Halep, Norduz, and Gokceada) and have good adaptation abilities. However, the Saanen breed has become increasingly common in recent years because of its higher milk yield. The most important source of income for goat breeders is milk production and the selling of male kids. However, traditional goat rearing programs (10-12 weeks) are quite long for dairy enterprises causing the loss of high volumes of marketable milk and the increase of milk production costs. Nowadays, goat milk and goat milk products (cheese, butter, ice-cream, etc.) can be marketed as niche products and buyers are willing to pay higher prices for these products. Goat milk is marketed at higher prices than cow milk which is considered as an advantage for the producers. To increase the total milk production, breeders wean kids at earlier age and rear them artificially on a commercial milk replacer. Depending on the enterprise's policy, most of the breeders which rear kids artificially, separate the kids from their dams during the first 7 days after birth or immediately after birth. Producers raise whole male kids, except stud, for the purpose of meat production and sell them at the end of the rearing period.

The effects of breed (Dhanda et al. 1999a; Ekiz et al. 2010), slaughter age/weight (Marichal et al. 2003; Peña et al. 2009; Ding et al. 2010), sex (Bonvillani et al. 2010;

Address for correspondence:

Hulya Yalcintan

Istanbul University, Veterinary Faculty

Department of Animal Breeding and Husbandry

Avcilar, 34320, Istanbul, Turkey 
Kaić et al. 2012) and management system (Dhanda et al. 1999b) on goat carcass and meat quality have been widely studied. However, several studies have addressed the effect of the rearing type on the kids' meat quality (Argüello et al. 2005; Panea et al. 2012). In these studies, sensory analysis as an eating quality trait has not been investigated adequately (Zurita-Herrera et al. 2013), although $\mathrm{pH}$, tenderness, water holding capacity (WHC) and colour have been extensively investigated.

The purpose of the present study was to compare certain carcass and meat quality traits and sensory characteristics of Saanen kids reared with their dams and reared artificially. The effects of the slaughter age on carcass and meat quality characteristics were also investigated.

\section{Materials and Methods}

Forty-two male Saanen kids from the private dairy enterprise located in Istanbul (Evla Goat Farm, Catalca, Istanbul, Turkey) were raised under two different rearing types as natural rearing (NR) and artificial rearing (AR) and were slaughtered at 80 and 120 days of age. Therefore, we obtained 4 experimental groups: AR- 80 (n $=12)$, AR-120 $(n=12)$, NR-80 $(n=9)$ and NR-120 $(n=9)$. Goat kids in subgroups in the study were chosen immediately after kidding.

In the scope of routine management practices of the farm, the kids were separated from their dams immediately after kidding to form the artificial group of the study. Kids in the AR group received colostrum for the first two days by a nursing bottle. When the kids reached 3 days of age they were placed into $2.90 \times 2.90 \mathrm{~m}$ pens, which can shelter a maximum of 12 kids. The kids were fed by a milk feeder bucket with a mix of $70 \%$ dam's milk and $30 \%$ commercial milk replacer $(350 \mathrm{ml} \times 3$ per day) from 3 days after kidding. Fifty percent dam's milk was mixed with a $50 \%$ commercial milk replacer $(350 \mathrm{ml} \times 3$ per day) and supplied to the kids from 7 days after kidding. The kids were then fed with a $100 \%$ milk replacer from $11^{\text {th }}$ days after kidding until 80 days of age. Two milk feeder buckets with 6 nipples were supplied for each pen thus each kid could receive one nipple. Milk feeder buckets were cleaned after each use. After the age of 21 days, concentrate feed and dry grass were supplied in addition to the milk replacer. Kids in the AR group were weaned from the milk replacer at the mean age of 83 days according to the management routine of the farm.

Kids in the NR group were kept with their dams until the age of 45 days receiving dam's milk. The dimensions of the indoor box where the dams and their kids were kept was $4 \times 6.9$ m and the dimensions of the backyard were $4 \times 6.7 \mathrm{~m}$. The second week following the kidding, concentrate feed and dry grass were supplied constantly in the box where only the kids had access. Kids in the NR group were separated from their dams at the age of 45 days and were placed into pens with the size of $2.9 \times 2.9 \mathrm{~m}$. Concentrate feed and dry grass were supplied constantly until the age of 80 days. Kids in AR- 80 and NR-80 were sent for slaughter when they reached 83 days of age. After the age of 83 days, kids in AR-120 and NR-120 subgroups were placed into pens with the size of $2.9 \times 2.9$ $\mathrm{m}$ and fattened until the slaughter age of 120 days. During the fattening period, concentrate feed and dry grass were supplied to the animals constantly. Feed composition of concentrate feed and dry grass supplied to kids in different periods of growth are shown in Table 1. Kids' growth performance was monitored by weekly weighing.

Table 1. Chemical composition of commercial milk replacer, concentrated feeds and hay.

\begin{tabular}{lcccc}
\hline Chemical composition & $\begin{array}{c}\text { Commercial } \\
\text { milk replacer }\end{array}$ & $\begin{array}{c}\text { Starter concentrate } \\
\text { feed }^{\mathrm{a}}\end{array}$ & $\begin{array}{c}\text { Grower concentrate } \\
\text { feed }^{\mathrm{b}}\end{array}$ & Hay \\
\hline Dry matter, \% & 95.5 & 86.9 & 87.5 & 88.5 \\
Crude protein, \% & 23.13 & 17.69 & 14.31 & 7.13 \\
Ether extract, \% & 17.6 & 4.82 & 4.61 & 0.42 \\
Crude cellulose, \% & 1.58 & 6.58 & 6.79 & 29.9 \\
Ash, \% & 2.58 & 6.78 & 7.88 & 5.89 \\
NDF, \% & 6.12 & 26.65 & 28.69 & 67.15 \\
ADF, \% & 2.12 & 9.69 & 11.05 & 43.88 \\
Metabolizable energy & 15.46 & 11.24 & 11.09 & 8.81 \\
(MJ/kg dry matter) & & & \\
\hline
\end{tabular}

${ }^{a}$ Concentrate feed given to kids until 80 days of age

${ }^{\mathrm{b}}$ Concentrate feed given to kids after 80 days of age

$\mathrm{NDF}$ - neutral detergent fibre; ADF - acid detergent fibre 
The kids had a resting period of $30 \mathrm{~min}$ after they were transported to the abattoir, and their weights were recorded before slaughter. Hot carcass weights were recorded after removing and weighing the non-carcass components. The empty body weight was calculated by subtracting the contents of the gastro-intestinal tract from pre-slaughter live weight. The dressing percentage was calculated by concerning both the pre-slaughter live weight and empty body weight. After chilling the carcasses at $4{ }^{\circ} \mathrm{C}$ for $24 \mathrm{~h}$, the carcass length, leg length, buttock width, buttock circumference, thoracic circumference and thoracic depth were determined in accordance with Ekiz et al. (2010). The methodology described by Colomer-Rocher (1984) was used to determine the subjective fatness grading and conformation scores of carcasses. The longissimus dorsi (LD) muscle section area was measured between the $12-13^{\text {th }}$ vertebrae from the half carcass.

The LD and semimembranosus (SM) muscles were removed from the right sides of the carcasses at $24 \mathrm{~h}$ postslaughter and meat samples were collected after ageing the muscle for $72 \mathrm{~h}$ at $4{ }^{\circ} \mathrm{C}$ for meat quality analyses. After the meat ageing process the drip loss, expressed juice, cooking loss and Warner-Bratzler (WB) shear force evaluation were performed with the meat samples obtained from the LD muscle, while the sensory evaluation was performed with the meat samples obtained from the SM muscle. For sensory evaluation, the meat samples were packed under vacuum, frozen and kept at $-18^{\circ} \mathrm{C}$ until panel evaluation.

Carcass $\mathrm{pH}$ was measured between the $12-13^{\text {th }}$ vertebrae in the LD muscle immediately after carcass dressing $\left(\mathrm{pH}_{0}\right)$ and $24 \mathrm{~h}$ after chilling at $4{ }^{\circ} \mathrm{C}$ in cold storage room $\left(\mathrm{pH}_{24 \mathrm{~h}}\right)$ by using TESTO-205 digital $\mathrm{pH}$ meter (Testo-AG, Lenzkirch, Germany). Drip loss was determined according to the methodology described by Ekiz et al. (2010) and cooking loss was measured in accordance with Dhanda et al. (1999a). Modified Grau and Hamm methodology which was described by Beriain et al. (2000) was used to measure the expressed juice. The texture of meat samples was determined by using Instron Universal Testing Machine (Model 3343, Instron Corp., Norwood, MA, USA) equipped with Warner-Bratzler blade. Peak WB shear force value for an individual was calculated by the average of shear force values obtained from total samples (Ekiz et al. 2010). Meat colour variables (L*, a*, b*) were measured $1 \mathrm{~h}$ and $24 \mathrm{~h}$ after cutting by using a Minolta CR 400 chronometer (Minolta Camera Co., Osaka, Japan). During this process, meat samples in plastic trays were wrapped with oxygen permeable PVC film and stored at $4{ }^{\circ} \mathrm{C}$ under white light.

A day prior to each panel session, SM muscle samples were taken from the freezer and thawed at $4{ }^{\circ} \mathrm{C}$. Meat samples, which were served to the panellists, were prepared according to the methodology described by Ekiz et al. (2010). Panel evaluation was carried out in five sessions and two sub-samples from all study groups were served to panellists for the first three sessions. Two sub-samples from NR-80 and NR-120 groups, three subsamples from AR-80 and AR-120 groups were served in the fourth panel session. In the fifth panel session, from NR-80 and NR-120 group one sub-sample for each and 3 sub-samples for AR-80 and AR-120 groups were served to the panellists. Sensory characteristics of cooked samples were assessed by seven panellists using an eight-point category scale described by Sañudo et al. (1998).

In order to determine the effects of slaughter age and rearing type on the slaughter, carcass and instrumental meat quality traits, General Linear Model (GLM) was applied by using SPSS 13.0 programme. The initial mathematical model used in the analyses of sensory characteristics was:

$\left.\left.\left.\left.\mathrm{Y}_{\mathrm{ijklm}}=\mu+\mathrm{SA}_{\mathrm{i}}+\mathrm{RT}_{\mathrm{j}}+\mathrm{P}_{\mathrm{k}}+\mathrm{S}_{1}+\mathrm{SART}_{\mathrm{ij}}\right)+\mathrm{SAP}_{(\mathrm{ik}}\right)+\mathrm{SAS}_{\mathrm{il}}\right)+\mathrm{RTP}\left(\mathrm{jk}_{\mathrm{j}}\right)+\operatorname{RTS}_{(\mathrm{jl}}\right)+\operatorname{PS}\left({ }_{\mathrm{kl}}\right)+\mathrm{e}_{\mathrm{ijklm}}$

where $\mathrm{Y}_{\mathrm{ijklm}}$ is meat sensory characteristics; $\mu$ is the overall mean; $\mathrm{SA}_{\mathrm{i}}$ is the fixed effect of slaughter age $(\mathrm{i}=80$ $\mathrm{d}, 120-\mathrm{d}) ; \mathrm{RT}_{\mathrm{j}}$ is the fixed effect of rearing type $(\mathrm{j}=$ natural, artificial $) ; \mathrm{P}_{\mathrm{k}}$ is the fixed effect of panellist $(\mathrm{k}=1$, $\ldots, 7) ; \mathrm{S}_{1}$ is the fixed effect of session $(1=1,2,3,4,5) ; \operatorname{SART}\left({ }_{\mathrm{ij}}\right), \operatorname{SAP}\left({ }_{\mathrm{ik}}\right), \operatorname{SAS}\left({ }_{\mathrm{il}}\right), \operatorname{RTP}\left({ }_{\mathrm{jk}}\right), \operatorname{RTS}\left({ }_{\mathrm{jl}}\right)$ and $\operatorname{PS}\left({ }_{\mathrm{kl}}\right)$ are interaction effects; $\mathrm{e}_{\mathrm{ijklm}}$ is residual random error. If an interaction term was not significant, it was excluded from the model.

\section{Results}

The effects of slaughter age and rearing type on the kids' average daily gain (ADG), slaughter and carcass characteristics are presented in Table 2. Kids slaughtered at 120 days of age (SA-120) presented a higher slaughter weight, hot carcass weight and empty body weight compared to kids slaughtered at 80 days of age (SA-80). However, there were no significant differences between slaughter age groups in terms of commercial and real dressing percentages.

The SA-120 kids had higher carcass length, buttock circumference, thoracic circumference, thoracic depth and conformation score than SA-80 kids, while the slaughter age had no significant effect on the leg length, buttock width, LD area and fatness score. On the other hand, there were no significant differences between NR and AR kids with regard to these traits, except leg length. The AR kids had higher leg length compared to NR kids (data not shown in tables). 
Table 2. Average daily gain, slaughter and carcass characteristics of Saanen goat kids according to the slaughter age and rearing type (data expressed as least squares means \pm standard error).

\begin{tabular}{|c|c|c|c|c|c|c|c|}
\hline \multirow{2}{*}{ Characteristics } & \multicolumn{2}{|c|}{ Slaughter age (SA) } & \multicolumn{2}{|c|}{ Rearing type (RT) } & \multirow{2}{*}{ SA } & \multirow{2}{*}{ RT } & \multirow{2}{*}{$\mathrm{SA} \times \mathrm{RT}$} \\
\hline & SA-80 & SA-120 & Natural & Artificial & & & \\
\hline $\mathrm{ADG}^{\mathrm{e}}, \mathrm{d} / \mathrm{g}$ & $86.89 \pm 4.88$ & $83.74 \pm 4.88$ & $81.59 \pm 5.22$ & $89.04 \pm 4.52$ & NS & NS & NS \\
\hline Slaughter weight, $\mathrm{kg}$ & $10.56 \pm 0.54$ & $13.23 \pm 0.54$ & $11.73 \pm 0.58$ & $12.05 \pm 0.50$ & $* *$ & NS & NS \\
\hline Empty body weight, $\mathrm{kg}$ & $8.26 \pm 0.45$ & $10.03 \pm 0.45$ & $9.28 \pm 0.49$ & $9.01 \pm 0.42$ & $* *$ & NS & NS \\
\hline Hot carcass weight, $\mathrm{kg}$ & $3.97 \pm 0.25$ & $4.86 \pm 0.25$ & $4.42 \pm 0.27$ & $4.42 \pm .023$ & $*$ & NS & NS \\
\hline Commercial dressing, $\%$ & $37.51 \pm 0.67$ & $36.54 \pm 0.67$ & $37.60 \pm 0.71$ & $36.44 \pm 0.62$ & NS & NS & NS \\
\hline Real dressing, $\%$ & $47.95 \pm 0.43$ & $48.18 \pm 0.43$ & $47.38 \pm 0.46$ & $48.74 \pm 0.40$ & NS & * & * \\
\hline Natural & $46.43^{b} \pm 0.79$ & $48.32^{\mathrm{a}} \pm 0.55$ & & & & & \\
\hline Artificial & $49.46^{a} \pm 0.39$ & $48.03^{\mathrm{ab}} \pm 0.67$ & & & & & \\
\hline Empty stomachs, $\%$ & $5.16 \pm 0.16$ & $5.21 \pm 0.16$ & $5.08 \pm 0.17$ & $5.29 \pm 0.15$ & NS & NS & NS \\
\hline Empty intestine, $\%$ & $9.91 \pm 0.25$ & $8.67 \pm 0.25$ & $9.33 \pm 0.27$ & $9.25 \pm 0.23$ & $* *$ & NS & * \\
\hline Natural & $10.37^{\mathrm{a}} \pm 0.54$ & $8.28^{c} \pm 0.33$ & & & & & \\
\hline Artificial & $9.44^{\mathrm{ab}} \pm 0.29$ & $9.06^{\mathrm{bc}} \pm 0.28$ & & & & & \\
\hline Gastro-intestinal tract & & & & & & & \\
\hline content, $\%$ & $21.72 \pm 0.97$ & $24.26 \pm 0.97$ & $20.57 \pm 1.04$ & $25.41 \pm 0.90$ & NS & $*$ & NS \\
\hline
\end{tabular}

NS: Not significant $(P>0.05) ; *: P<0.05 ; * *: P<0.01$

a,b,c Means for SA $\times$ RT subgroups with different superscript letters following them are significantly different $(P<0.05)$

${ }^{\mathrm{e}}$ Average daily gain between birth and slaughter age

Table 3. The $\mathrm{pH}$, drip loss, expressed juice, cooking loss, Warner-Bratzler (WB) shear force values and meat colour variables of meat from Saanen goat kids according to slaughter age and rearing type (data expressed as least squares means \pm standard error).

\begin{tabular}{|c|c|c|c|c|c|c|c|}
\hline \multirow{2}{*}{ Characteristics } & \multicolumn{2}{|c|}{ Slaughter age (SA) } & \multicolumn{2}{|c|}{ Rearing type (RT) } & \multirow{2}{*}{ SA } & \multirow{2}{*}{ RT } & \multirow{2}{*}{$\mathrm{SA} \times \mathrm{RT}$} \\
\hline & SA-80 & SA-120 & Natural & Artificial & & & \\
\hline $\mathrm{pH}_{0}$ & $6.36 \pm 0.04$ & $6.40 \pm 0.04$ & $6.40 \pm 0.04$ & $6.37 \pm 0.03$ & NS & NS & NS \\
\hline $\mathrm{pH}_{24 \mathrm{~h}}$ & $5.94 \pm 0.05$ & $6.10 \pm 0.05$ & $6.03 \pm 0.05$ & $6.01 \pm 0.05$ & $*$ & NS & NS \\
\hline $\mathrm{pH}_{0-24 h}^{\mathrm{j}}$ & $0.43 \pm 0.05$ & $0.30 \pm 0.05$ & $0.37 \pm 0.05$ & $0.36 \pm 0.04$ & NS & NS & NS \\
\hline Drip loss, $\%$ & $3.67 \pm 0.29$ & $3.49 \pm 0.29$ & $3.72 \pm 0.31$ & $3.46 \pm 0.26$ & NS & NS & NS \\
\hline Expressed juice, $\%$ & $6.74 \pm 0.68$ & $5.65 \pm 0.68$ & $6.31 \pm 0.73$ & $6.08 \pm 0.63$ & NS & NS & NS \\
\hline Cooking loss, $\%$ & $24.33 \pm 0.99$ & $25.67 \pm 0.95$ & $25.79 \pm 1.02$ & $24.21 \pm 0.92$ & NS & NS & NS \\
\hline WB shear force, $\mathrm{kg}$ & $2.46 \pm 0.33$ & $4.33 \pm 0.33$ & $3.34 \pm 0.36$ & $3.46 \pm 0.31$ & $* * *$ & NS & NS \\
\hline \multicolumn{8}{|c|}{ Colour indicators at $1 \mathrm{~h}$} \\
\hline$\left(\mathrm{L}^{*}\right)_{\mathrm{lh}}$ & $45.88 \pm 0.61$ & $45.46 \pm 0.61$ & $46.97 \pm 0.65$ & $44.36 \pm 0.57$ & NS & $* *$ & NS \\
\hline$\left(a^{*}\right)_{1 \mathrm{~h}}$ & $15.31 \pm 0.73$ & $15.39 \pm 0.73$ & $14.70 \pm 0.78$ & $15.99 \pm 0.67$ & NS & NS & NS \\
\hline$\left(b^{*}\right)_{1 \mathrm{~h}}$ & $4.08 \pm 0.31$ & $4.38 \pm 0.31$ & $4.60 \pm 0.33$ & $3.87 \pm 0.28$ & NS & NS & NS \\
\hline$\left(C^{*}\right)_{1 h}$ & $15.87 \pm 0.76$ & $16.03 \pm 0.76$ & $15.43 \pm 0.82$ & $16.47 \pm 0.71$ & NS & NS & NS \\
\hline$\left(\mathrm{H}^{*}\right)_{1 \mathrm{~h}}$ & $14.60 \pm 0.75$ & $16.06 \pm 0.75$ & $17.42 \pm 0.80$ & $13.25 \pm 0.69$ & NS & $* * *$ & NS \\
\hline \multicolumn{8}{|c|}{ Colour indicators at $24 \mathrm{~h}$} \\
\hline$\left(\mathrm{L}^{*}\right)_{24 \mathrm{~h}}$ & $47.57 \pm 0.50$ & $46.67 \pm 0.50$ & $47.50 \pm 0.54$ & $45.74 \pm 0.46$ & $*$ & $*$ & NS \\
\hline$\left(a^{*}\right)_{24 \mathrm{~h}}$ & $16.20 \pm 0.88$ & $17.26 \pm 0.88$ & $16.05 \pm 0.94$ & $17.41 \pm 0.81$ & NS & NS & NS \\
\hline$\left(b^{*}\right)_{24 h}^{241}$ & $7.09 \pm 0.32$ & $7.44 \pm 0.32$ & $7.65 \pm 0.34$ & $6.87 \pm 0.30$ & NS & NS & NS \\
\hline$\left(C^{*}\right)_{24 \mathrm{~h}}$ & $17.72 \pm 0.90$ & $18.84 \pm 0.90$ & $17.81 \pm 0.96$ & $18.76 \pm 0.83$ & NS & NS & NS \\
\hline$\left(\mathrm{H}^{*}\right)_{24 \mathrm{~h}}$ & $23.90 \pm 0.83$ & $23.85 \pm 0.83$ & $25.87 \pm 0.89$ & $21.88 \pm 0.77$ & NS & $* *$ & NS \\
\hline
\end{tabular}

NS: Not significant $(P>0.05) ;{ }^{*}: P<0.05 ; * *: P<0.01 ; * * *: P<0.001 ;{ }^{\mathrm{j}} \mathrm{pH}_{0-24 \mathrm{~h}}=\mathrm{pH}_{0}-\mathrm{pH}_{24 \mathrm{~h}}$ 
Mean values of meat $\mathrm{pH}$, drip loss, expressed juice, cooking loss, WB shear force values and meat colour variables are shown in Table 3. The SA-120 kids had higher $\mathrm{pH}_{24}$ and WB shear force values than the SA-80 kids. Meat of the NR kids had higher Lightness and Hue values than that of the AR kids at $1 \mathrm{~h}$ and $24 \mathrm{~h}$ after cutting. On the other hand, slaughter age did not affect meat colour indicators significantly, except for meat lightness ( $\left.\mathrm{L}^{*}\right)$ at $24 \mathrm{~h}$ after cutting.

The effect of the rearing type and slaughter age on the meat sensory characteristics are presented in Table 4. Higher scores were given to the meat samples from SA-80 kids for tenderness by panellists. Compared to those of NR kids, AR kids had lower scores for tenderness and juiciness.

Table 4. Meat sensory characteristics of Saanen goat kids according to slaughter age and rearing type (data expressed as least squares means \pm standard error).

\begin{tabular}{|c|c|c|c|c|c|c|c|}
\hline \multirow{2}{*}{ Characteristics } & \multicolumn{2}{|c|}{ Slaughter age (SA) } & \multicolumn{2}{|c|}{ Rearing type (RT) } & \multirow{2}{*}{ SA } & \multirow{2}{*}{ RT } & \multirow{2}{*}{$\mathrm{SA} \times \mathrm{RT}$} \\
\hline & SA-80 & SA-120 & Natural & Artificial & & & \\
\hline Odour intensity & $4.36 \pm 0.09$ & $4.46 \pm 0.09$ & $4.48 \pm 0.09$ & $4.34 \pm 0.08$ & NS & NS & NS \\
\hline Tenderness & $5.08 \pm 0.12$ & $3.73 \pm 0.12$ & $4.60 \pm 0.13$ & $4.21 \pm 0.11$ & $* * *$ & * & NS \\
\hline Juiciness & $4.75 \pm 0.26$ & $4.79 \pm 0.27$ & $5.25 \pm 0.29$ & $4.29 \pm 0.25$ & NS & $*$ & NS \\
\hline Flavour intensity & $4.57 \pm 0.09$ & $4.39 \pm 0.09$ & $4.49 \pm 0.10$ & $4.46 \pm 0.09$ & NS & NS & NS \\
\hline
\end{tabular}

NS: Not significant $(P>0.05) ; *: P<0.05 ; * * *: P<0.001$

${ }^{\mathrm{k} S c a l e} 1$ = non odour, extremely tough, extremely dry and no flavour; scale $8=$ very strong odour, extremely tender, extremely juicy and very strong flavour.

\section{Discussion}

The average daily gain from birth to slaughter age were similar in all subgroups. However, the slaughter weight, hot carcass weight and empty body weight increased with the increasing slaughter age. Supporting these results, several authors (Argüello et al. 2007; Peña et al. 2007; Bonvillani et al. 2010) reported an increase in empty body weight and hot carcass weight with the increasing slaughter age/slaughter weight. Commercial and real dressing percentages did not change with the increasing slaughter weight in the current study as previously reported by Peña et al. (2007), Kaić et al. (2012), and Panea et al. (2012). In contrast, Argüello et al. (2007) found a higher dressing percentage in heavier kids than in lighter kids and explained this difference by a lower proportion of liver and head in the heavier kids. Dressing percentage is affected by the proportion of non-carcass components, carcass fatness and the content of gastro-intestinal tract (Argüello et al. 2007; Ekiz et al. 2010). In the current study, dressing percentage was calculated according to slaughter weight and also empty body weight trying thus to prevent the dressing percentage from being affected by the content of gastro-intestinal tract. Moreover, there were no differences between SA-120 and SA-80 kids in terms of carcass fatness. Similar to the current results, Teixeira et al. (2011) pointed out that the dressing percentage did not change in light kids, which had 3.8-6 kg carcass weight. Commercial and real dressing percentages were in the range of $35-38 \%$ and $47-49 \%$, respectively. These values were lower than previous literature reports for dressing percentages in kids (Peña et al. 2009; Bonvillani et al. 2010; Panea et al. 2012). It is known that inadequate growth rates in kids which are slaughtered at lower live weights cause lower dressing percentages (Fehr et al. 1976).

There were significant increases in the linear carcass measurements and conformation scores with increasing slaughter age in the current study except for the leg length and 
buttock width. Similarly, increases in carcass measurements with slaughter weight/ slaughter age were reported by Panea et al. (2012) for seven different Spanish goat breeds and by Kaić et al. (2012) for Boer goat kids. Moreover, increases in conformation score with slaughter weight were also reported by Bonvillani et al. (2010) for Criollo Cordobés goat kids and by Peña et al. (2007) for Florida goat kids. Differences between the slaughter age groups in subjective fatness scores were not significant in the current study. Possible reasons for this result may be that the kids did not reach maturity or the kids' diet did not include proper energy to store fat. Moreover, it is known that subcutaneous fat develops slowly in goats (Panea et al. 2012). Supporting the current result, Marichal et al. (2003) reported that there were no significant differences between Canary Caprine kids, which were slaughtered at 6,10 and $25 \mathrm{~kg}$ live weights, in terms of subcutaneous fat percentages. On the other hand, various authors have observed increases in carcass fatness with age (Dhanda et al. 1999b; Peña et al. 2007). Differences between results of the studies in carcass fatness may be due to the differences in breed, feeding methods and slaughter weights.

The rearing type had no significant effect on the slaughter weight, hot carcass weight, empty body weight and commercial dressing percentage in the present study, in accordance to the report by Argüello et al. (2007) for Canary Caprine kids. Similarly, Panea et al. (2012) observed that the effects of milk diet (natural and artificial) on the live weight, carcass weight and dressing percentages were not significant for Malagueña and MurcianoGranadina dairy goat breeds. On the other hand, SA $\times$ RT interaction was significant for real dressing percentage in the current study. Natural reared SA-120 kids had higher real dressing percentage than natural reared SA-80 kids. This difference in real dressing percentage could be due to higher empty intestine percentage of natural SA- 80 kids.

The SA-120 kids had higher $\mathrm{pH}_{24}$ and WB shear force values than the SA-80 kids. Final $\mathrm{pH}$ value is the main indicator of meat quality commercially and effects on instrumental meat quality characteristics (Simela et al. 2004; Ekiz et al. 2012). Acceptable meat tenderness and colour appear as a consequence of an ideal pH (Simela et al. 2004). In the present study, the final $\mathrm{pH}\left(\mathrm{pH}_{24 \mathrm{~h}}\right)$ values of the SA-120 kids were higher than 6.0, which are connected with lower meat quality. Furthermore, the SA-80 kids also had a high final $\mathrm{pH}$ value (5.94). High final $\mathrm{pH}$ values for goat muscles are prevalent in literature (Webb et al. 2005). The reason for a high $\mathrm{pH}$ level in goats may be explained by several ways; firstly, goats are highly prone to stress and generally have lower pre-slaughter live weight which results with decreasing muscle glycogen storage and the final $\mathrm{pH}$ remains high (Priolo et al. 2001; Webb et al. 2005). Furthermore, they have lean carcasses with low carcass fatness. Lean carcasses allow the muscle a rapid chilling rate and rigor mortis is attained at lower temperatures and final $\mathrm{pH}$ remains high (Priolo et al. 2001).

The result of the WB shear force and meat colour analyses suggest that meat from the SA-120 kids was tougher (higher WB values) and darker (lower L* values at $24 \mathrm{~h}$ after cutting) than meat from the SA-80 kids. It is known that there is a negative correlation between the meat colour lightness $\left(\mathrm{L}^{*}\right)$ and the final $\mathrm{pH}$ value (Sañudo et al. 2012). Also, lower $\mathrm{pH}$ value is related to higher tenderness (Simela et al. 2004). High final pH values in the SA-120 kids might have an influence on the WB shear force values and meat colour at $24 \mathrm{~h}$ after cutting.

Meat from natural reared kids had higher lightness $\left(\mathrm{L}^{*}\right)$ and Hue angle $\left(\mathrm{H}^{*}\right)$ values $1 \mathrm{~h}$ and $24 \mathrm{~h}$ after cutting than those of artificial reared kids. Meat colour is not an important eating quality characteristic, but it is a major factor in the initial selection of meat by the consumers (Beriain et al. 2000; Priolo et al. 2001). Consumers mostly prefer light or pink meat in Turkey, as well as in most other Mediterranean countries (Ekiz et al. 2012). Similar rearing type effect on meat lightness was reported by Osorio et al. (2008) for lambs previously. Authors attributed these results to differences in the intramuscular fat 
content between natural and artificial rearing groups. However, the feeding of lambs with maternal milk also results in pale meat because of lack of iron in maternal milk (Sañudo et al. 2012). Maternal milk consumption could be one of the reasons for the difference in meat lightness between the NR and AR kids. On the other hand, the effect of the rearing type on meat lightness has not always been detected. Argüello et al. (2005) and ZuritaHerrera et al. (2013) found no significant effect of the rearing type on meat lightness in the LD muscle.

Higher scores were given to meat samples from SA-80 kids for tenderness by panellists. Compared to those of NR kids, AR kids had lower scores for tenderness and juiciness. Tenderness of the cooked meat is one of the most important sensory characteristics for consumer satisfaction (Argüello et al. 2005). The panel results for meat tenderness in the slaughter age groups were consistent with the results for WB shear force analysis. These results are in agreement with Ding et al. (2010) who reported a negative correlation between meat tenderness and slaughter age. It is also known that insoluble collagen content of meat increases with age and results in tougher meat (Marichal et al. 2003; Webb et al. 2005). In the present study, panellists did not find any significant differences between groups in terms of flavour intensity. Peña et al. (2009) and Ding et al. (2010) also observed that the slaughter weight/age had no effect on flavour. Previous observations of Os orio et al. (2008) indicated that flavour could be related to the fatty acid composition of the meat.

The NR kids produced more tender and juicy meat than AR kids in the current study. Supporting this result, Ekiz et al. (2012) found improved sensory tenderness scores with increasing suckling length. Meat juiciness is directly related to the intramuscular fat content (Webb et al. 2005). Unfortunately, we did not determine the collagen or intramuscular fat content in the current study. When results of the other studies are considered, the difference between groups in terms of tenderness and juiciness may be explained by the variation in age and intramuscular fat content together.

The rearing type had no effect on the ADG, slaughter weight, empty body weight, carcass weight, commercial dressing percentage, omental and mesenteric fat percentage, carcass length, LD muscle area, conformation and fatness scores as well as instrumental meat quality traits. The slaughter weight, empty body weight, hot carcass weight, carcass length, conformation score, final $\mathrm{pH}$ and $\mathrm{WB}$ shear force values increased with slaughter age, while tenderness score decreased. By taking these results into account, it may be concluded that the slaughter age had a greater effect on the carcass and meat quality characteristics than the rearing type. Breeders who aim to get a high milk yield can rear Saanen goat kids artificially and slaughter them at 80 days of age without causing any negative effects on carcass and meat quality characteristics.

\section{Acknowledgements}

The study was supported by the Scientific Research Projects Coordination Unit of Istanbul University (Project Number: 41327 and BEK-24711).

\section{References}

Argüello A, Castro N, Capote J, Solomon M 2005: Effects of diet and live weight at slaughter on kid meat quality. Meat Sci 70: 173-179

Argüello A, Castro N, Capote J, Solomon MB 2007: The influence of artificial rearing and live weight at slaughter on kid carcass characteristics. J Anim Vet Adv 6: 20-25

Beriain MJ, Horcada A, Purroy A, Lizaso G, Chasco J, Mendizabal JA 2000: Characteristics of Lacha and Rasa Aragonesa lambs slaughtered at three weights. J Anim Sci 78: 3070-3077

Bonvillani A, Peña F, de Gea G, Gómez G, Petryna A, Perea J 2010: Carcass characteristics of Criolla Cordobés kid goats under an extensive management system: Effects of gender and liveweight at slaughter. Meat Sci 86: 651-659

Colomer-Rocher F 1984: Methodology for the classification of sheep carcasses. Madrid, Spain: Oleaginosas Españolas S.A. Spanish. 
Dhanda JS, Taylor DG, McCosker JE, Murray PJ 1999a: The influence of goat genotype on the production of Capretto and Chevon carcasses. 2. Meat Quality. Meat Sci 52: 363-367

Dhanda JS, Taylor DG, McCosker JE, Murray PJ 1999b: The influence of goat genotype on the production of Capretto and Chevon carcasses. 1. Growth and carcass characteristics. Meat Sci 52: 355-361

Ding W, Kou L, Cao B, Wei Y 2010: Meat quality parameters of descendants by grading hybridization of Boer goat and Guanzhong Dairy goat. Meat Sci 84: 323-328

Ekiz B, Ergül Ekiz E, Yalcintan H, Kocak O, Yilmaz A 2012: Effects of suckling length (45, 75 and 120d) and rearing type on cortisol level, carcass and meat quality characteristics in Kivircik lambs. Meat Sci 92: 53-61

Ekiz B, Ozcan M, Yilmaz A, Tölü C, Savas T 2010: Carcass measurements and meat quality characteristics of dairy suckling kids compared to an indigenous genotype. Meat Sci 85: 245-249

FAO 2014: Food and Agriculture Organization of the United Nations. Available at: http://www.fao.org/faostat/ en/\#data/QA. Accessed March 23, 2016.

Fehr PM, Sauvant D, Delage J, Dumont BL, Roy G 1976: Effect of feeding methods and age at slaughter on growth performances and carcass characteristics of entire young male goats. Livest Prod Sci 3: 183-194

Kaić A, Cividini A, Potočnik K 2012: Influence of sex and age at slaughter on growth performance and carcass traits of Boer kids. 20th International Symposium "Animal Science Days"; Sept 19-21; Kranjska gora. Slovenia: pp 281-285

Marichal A, Castro N, Capote J, Zamorano MJ, Argüello A 2003: Effects of live weight at slaughter (6, 10 and 25 $\mathrm{kg}$ ) on kid carcass and meat quality. Livest Prod Sci 83: 247-256

Osorio MT, Zumalacárregui JM, Cabeza EA, Figueira A, Mateo J 2008: Effect of rearing system on some meat quality traits and volatile compounds of suckling lamb meat. Small Rum Res 78: 1-12

Panea B, Ripoll G, Horcada A, Sañudo C, Teixeira A, Alcalde MJ 2012: Influence of breed, milk diet and slaughter weight on carcass traits of suckling kids from seven Spanish breeds. SJAR 10: 1025-1036

Peña F, Bonvillani A, Freire B, Juárez M, Perea J, Gómez G 2009: Effects of genotype and slaughter weight on the meat quality of Criollo Cordobes and Anglonubian kids produced under extensive feeding conditions. Meat Sci 83: 417-422

Peña F, Perea J, Garcia A, Acero R 2007: Effects of weight at slaughter and sex on the carcass characteristics of Florida suckling kids. Meat Sci 75: 543-550

Priolo A, Micol D, Agabriel J 2001: Effects of grass feeding systems on ruminant meat colour and flavour. A review. Animal Res 50: $185-200$

Sañudo C, Campo MM, Muela E, Oletta JL, Delfa R, Jiménez-Badillo R, Alcalde MJ, Horcada A, Oliveira I, Cilla I 2012: Carcass characteristics and instrumental meat quality of suckling kids and lambs. SJAR 10: 690-700

Sañudo C, Nute GR, Campo MM, María GA, Baker A, Sierra I, Enser ME, Wood JD 1998: Assessment of commercial lamb meat quality by British and Spanish taste panels. Meat Sci 48: 91-100

Simela L, Webb EC, Frylinck L 2004: Effect of sex, age and pre-slaughter conditioning on pH, temperature, tenderness and colour of indigenous South African goats. SASAS 34 Suppl: 208-211

Teixeira A, Jimenez-Badillo MR, Rodrigues S 2011: Effect of sex and weight on carcass traits and meat qaulity in goat kids of Cabrito Transmontano. SJAR 9: 753-760

Webb EC, Casey NH, Simela L 2005: Goat meat quality. Small Rum Res 60: 153-166

Zurita-Herrera P, Bermejo DJV, Henríquez AA, Vallejo MEC, Costa RG 2013: Effects of three management systems on meat quality of dairy breed goat kids. J Appl Anim Res 41: 173-182 